\title{
Development of New Methodologies Toward Green Sustainable Organic Electrode Processes
}

\author{
Toshio Fuchigami * and Toshiki TAJIMA \\ Department of Electronic Chemistry, Tokyo Institute of Technology (G1-2, 4259 Nagatsuta, Midori-ku, Yokohama \\ 226-8502, Japan)
}

Received March 15, 2006 ; Accepted May 17, 2006

\begin{abstract}
This article describes our recent results of electroorganic synthesis, especially focusing on new organic electrolytic systems toward green sustainable chemistry as follows: (a) Electroorganic synthesis using recyclable solid-supported bases, (b) electrocatalytic hydrogenation and dehalogenation using new electrolytic systems, (c) electrosynthesis of organofluorine compounds, conducting polymers, and others in ionic liquids.
\end{abstract}

Key Words : Green Sustainable Electrochemistry, Electroorganic Synthesis, Solid-Supported Base, Ionic Liquid

\section{Introduction}

Electroorganic synthesis has developed remarkably because it offers unique selectivity as well as high potentiality of realizing specific reactions. ${ }^{1,2)}$ In recent years, electroorganic synthesis has attracted much attention as an environmentally friendly process because electrons are inherently environmentally friendly reagents compared with conventional oxidizing and reducing reagents. In fact, BASF company in Germany has commercialized a paired electrosynthesis of $t$-butylbenzaldehyde and phthalide, ${ }^{3)}$ and they stated that organic electrosynthesis is one of the most promising "Green Sustainable Processes". However, conventional electrolysis generally requires large amounts of supporting electrolytes and organic solvents to provide sufficient electrical conductivity and solubilizing ability to the electrolytic media. In order to achieve "Green Sustainable Electrode Processes", development of new methodologies minimizing the amount of supporting electrolytes and organic solvents or avoiding their use is necessary. Alternatively, their recycling is also strongly demanded. On the other hand, electrochemical reactions are typical heterogeneous processes; therefore, mass transport of substrates to the electrode surface becomes very often a rate-determining step. In order to overcome this problem, efficient methods for enhancement of the mass transport are also highly required.

From these viewpoints, various new electrolytic systems and methodologies have been developed to date. In this article, our recent results of organic electrosynthesis are described, especially focusing on "Green Organic Electrochemistry".

\section{Organic Electrosynthesis Using Recyclable Solid-Supported Bases}

As mentioned above, large amounts of supporting electrolytes are necessary to provide sufficient electrical conductivity to the solvents for electrolysis. This very often causes separation problems in the reaction mixture work-up and problems of additional waste. In order to solve such problems, a capillary gap cell has been developed to minimize the addition of supporting electrolytes. ${ }^{4}$ ) On the other hand, a polymeric electron carrier system, ${ }^{5)}$ solid polymer electrolytes, ${ }^{6}$ an aqueous silica gel disperse system, ${ }^{7}$ and thermomorphic biphasic electroorganic synthesis ${ }^{8)}$ have been developed to eliminate the steps for the separation of supporting electrolytes. Furthermore, recently, electrochemical microreacters ${ }^{9)}$ and a thin-layer flow cell ${ }^{10)}$ have also been developed to conduct electroorganic synthesis without intentionally added supporting electrolytes.

With these facts in mind, quite recently, we have developed a novel electrolytic system using solid-supported bases (amines). In this system, solid-supported bases dissociate protic organic solvents like methanol and acetic acid to protons and anions, and the resulting protons act as the main carrier of an electronic charge via ammonium ions [Eqs. $(1,2)] .^{11)}$

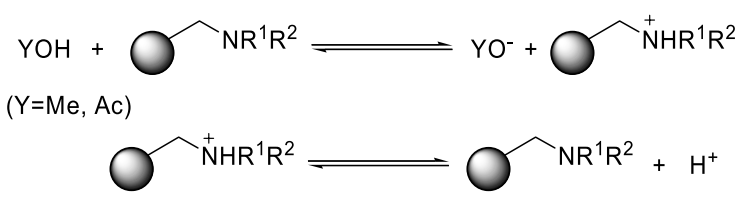

This system was successfully applied to various anodic nucleophilic substitutions. For example, anodic methoxy-

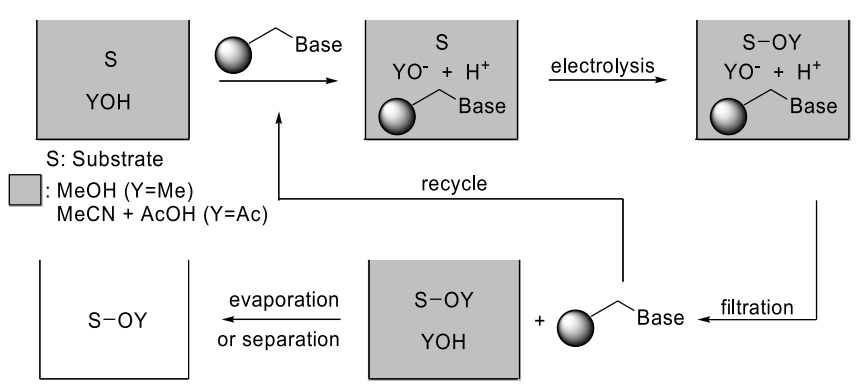

Fig. 1 Experimental Procedure 


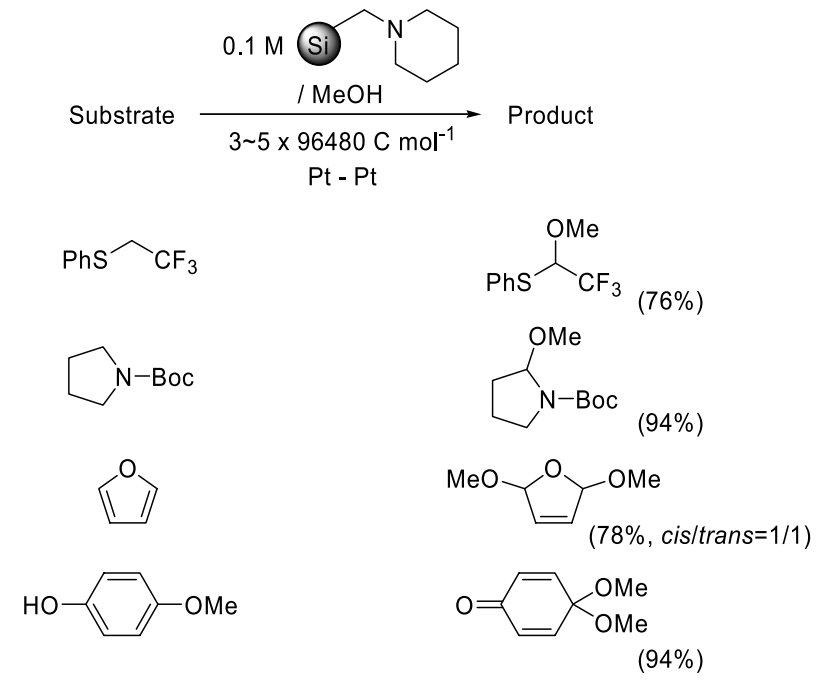

Scheme 1
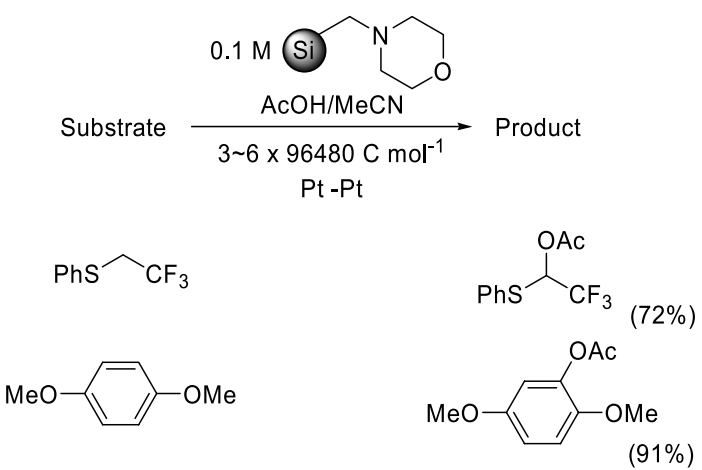

Scheme 2

lation $^{12,13)}$ and acetoxylation ${ }^{14)}$ of a variety of compounds were achieved in silica gel-supported piperidine/MeOH and silica gel-supported morpholine/AcOH/ $\mathrm{MeCN}$, respectively (Schemes 1 and 2). It is notable that after the electrolysis, silica gel-supported piperidine and morpholine are easily separated and recovered by only filtration, and reused many times (Fig. 1).

\section{Electrocatalytic Hydrogenation and Dehalogenation Using New Hydrogenation Systems}

In order to solve the separation problems of supporting electrolytes in the reaction mixture work-up, Iwakura and Inoue et al. developed a new hydrogenation system using a two-compartment reactor separated by a $\mathrm{Pd}$ sheet, which serves as a working electrode for water electrolysis to produce atomic hydrogen, a separator between compartments, a selectively permeable membrane of atomic hydrogen and a chemical reaction field for hydrogenation. ${ }^{15,16)}$ This system has been used for hydrogenation of various unsaturated organic compounds. However, due to slow mass transport of a substrate from a bulk solution to the cathode surface, current efficiency is not always satisfactory. ${ }^{17)}$ In order to overcome this problem, we have developed a novel flow

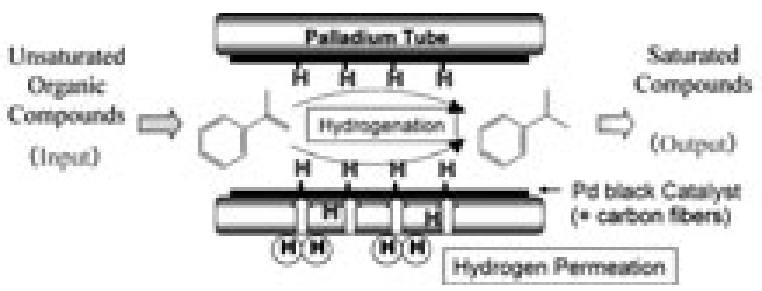

Fig. 2 Electrocatalytic Hydrogenation System

and circulating system using a $\mathrm{Pd}$ tube instead of the $\mathrm{Pd}$ sheet as shown in Fig. 2. ${ }^{18)}$ The Pd tube cathode is coated on the inside with Pd black and packed with a Pd catalyst supported on carbon fiber. A platinum cylindrical wire mesh anode surrounds the cathode. Both electrodes are immersed in a vessel containing an aqueous sulfuric acid solution. The solution of unsaturated organic compounds is circulated through the Pd tube using a pump. Water is electrolyzed at the outer wall of the cathode to produce hydrogen, which diffuses through the $\mathrm{Pd}$ as atomic hydrogen. On the other hand, oxygen is produced at the anode.

In a single pass, this system achieved a $100 \%$ hydrogenation current efficiency and chemical yield for a methanol solution containing $0.1 \mathrm{M}$ of various unsaturated compounds such as $\alpha$-methylstyrene, ethyl cinamate, and stilbene. Pure products can be obtained only by evaporation of the solutions without purification.

Furthermore, this new system was successfully used for dehalogenation of various halogenated aromatics such as harmful polychlorobenzenes.

\section{Electroorganic Synthesis in Ionic Liquids}

Most organic solvents are flammable and not always safe from health and environmental perspectives. In recent years, room-temperature molten salts, namely, ionic liquids, have proved to be a new class of promising solvents because of their excellent properties such as good electroconductivity, non-flammability, thermal stability, non-volatility, and reusability. ${ }^{19-21)}$ In addition, if a combination of cation and anion is appropriately made, aprotic media having a wide electrochemical window can be obtained. Therefore, when ionic liquids are used as electrolytic media, organic electrolytic reactions, particularly electroorganic synthesis should be possible without any organic solvents. ${ }^{22-24)}$

\section{1 Selective Anodic Fluorination in Ionic Liquids}

Partial fluorination, namely selective fluorination of organic compounds, is of much importance in order to develop new types of pharmaceuticals, agrochemicals, and functional materials. However, the selective fluorination is not straightforward and it very often requires hazardous and/or explosive reagents. On the other hand, selective anodic fluorination seems to be the most ideal method since it can be carried out under mild conditions without any hazardous reagents..$^{25-28)}$ The fluorination has usually been carried out in aprotic solvents containing $\mathrm{HF}$ salt ionic liquids such as $\mathrm{Et}_{3} \mathrm{~N} \cdot 3 \mathrm{HF}$ and $\mathrm{Et}_{4} \mathrm{NF}$. $3 \mathrm{HF}$. Since the discharge potential of fluoride ions is extremely high $(>+2.9 \mathrm{~V}$ vs. SCE at $\mathrm{Pt}$ anode in 


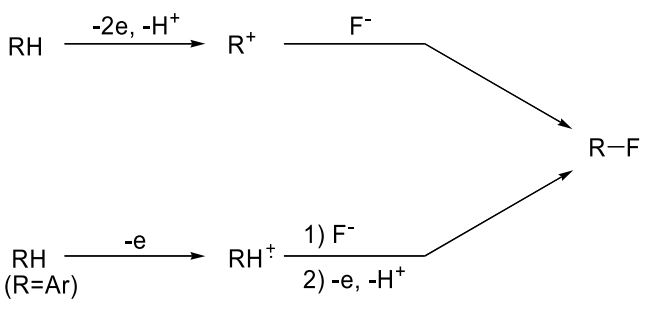

Scheme 3

$\mathrm{MeCN}$ ), the fluorination proceeds via a (radical) cation intermediate as shown in Scheme 3.

More than 15 years ago, we achieved anodic $\alpha$-fluorination of ethyl $\alpha$-phenylthioacetate (1) in $\mathrm{Et}_{3} \mathrm{~N} \cdot 3 \mathrm{HF} / \mathrm{MeCN}$ (Scheme 4). ${ }^{29)}$ This is the first successful example of selective anodic fluorination of heteroatom compounds. However, anodic difluorinaton of $\mathbf{1}$ was unsuccessful in the same electrolytic solution due to the oxidation of $\mathrm{Et}_{3} \mathrm{~N} \cdot 3 \mathrm{HF}$ prior to the substrate 1 . Quite recently, we have achieved highly selective anodic $\alpha, \alpha$-difluorination of $\mathbf{1}$ in neat $\mathrm{Et}_{3} \mathrm{~N} \cdot 3 \mathrm{HF}$ without a solvent under ultrasonication (Scheme 5). ${ }^{30)}$ Ultrasonication promotes markedly mass transport of $\mathbf{1}$ to the anode surface from the bulk of ionic liquid $\mathrm{Et}_{3} \mathrm{~N} \cdot 3 \mathrm{HF}$ and consequently the selective difluorination was realized. However, $\mathrm{Et}_{3} \mathrm{~N} \cdot 3 \mathrm{HF}$ is rather easily oxidized at around $2 \mathrm{~V}$ vs. $\mathrm{Ag} / \mathrm{Ag}^{+}$. Therefore, this ionic liquid is not suitable for the fluorination of substrates having high oxidation potentials.

Momota developed a new series of liquid fluoride salts, $\mathrm{R}_{4} \mathrm{NF} \cdot \mathrm{nHF}(\mathrm{R}=\mathrm{Me}, \mathrm{Et}$, and $\mathrm{n}-\mathrm{Pr}, \mathrm{n}>3.5)$ that are nonviscous liquids having high electroconductivity and anodic stability (up to $c a .3 \mathrm{~V}$ vs. $\mathrm{Ag} / \mathrm{Ag}^{+}$). ${ }^{31,32)}$ Yoneda reported that $\mathrm{Et}_{3} \mathrm{~N} \cdot 5 \mathrm{HF}$ is anodically stable up to $c a .3 \mathrm{~V}$ vs. $\mathrm{Ag} / \mathrm{Ag}^{+}{ }^{+33,34)}$ Although they successfully carried out anodic fluorination in such liquid fluoride salts, their solvent-free method has an atom economy problem because of the use of an excess amount of liquid salts in place of a solvent.

On the other hand, we found that the fluorination of ether substrates like tetrahydrofuran, 1,4-dioxane, 1,3dioxolane, and dimethoxyethane (DME) was achieved by anodic oxidation of a mixture of a large amount of liquid ethers and a small amount of $\mathrm{Et}_{4} \mathrm{NF} \cdot 4 \mathrm{HF}$ (only 1.5-1.7 equiv. of $\mathrm{F}^{-}$to the ether) at a high current density (150 $\mathrm{mA} \mathrm{cm}{ }^{-2}$ ) (Scheme 6). ${ }^{35,36)}$ In sharp contrast, the use of organic solvents or a large amount of $\mathrm{Et}_{4} \mathrm{NF} \cdot 4 \mathrm{HF}$ resulted in no formation or extremely low yield of the desired fluorinated product due to carbon-carbon bond cleavage and other side reactions. Cyclic and open-chain carbonates (Schemes 7, 8), lactones, and esters are also similarly fluorinated to provide the monofluorinated products in moderate to good yields. ${ }^{35,36)}$ It is notable that the fluorinated tetrahydrofuran and DME are easily isolated simply by distillation of the electrolytic ionic liquid fluoride salt after the electrolysis. Thus, completely solvent-free electroorganic synthesis was demonstrated by using liquid fluoride salt.

Moreover, we found that a combination of $\mathrm{Et}_{4} \mathrm{NF} \cdot 5 \mathrm{HF}$ and imidazolium triflate ionic liquids was highly effective for anodic fluorination of hardly oxidized phthalides (oxidation potential : $2.81 \mathrm{~V}$ vs. SCE) (Scheme 9). ${ }^{37)}$

It appears that ionic liquid [EMIM][OTf] enhances the electrophilicity of a cationic intermediate $\mathbf{A}$, which readily reacts with $\mathrm{F}^{-}$to provide the fluorinated phthalide in good yield as shown in Scheme 9.

Previously, we found that DME was suitable for anodic fluorination since DME enhances the nucleophilicity of fluoride ions. ${ }^{38,39)}$ We also found that DME stabilizes the cationic species while dichloromethane destabilizes them. ${ }^{40)}$ We investigated solvent effects of ionic liquids on anodic fluorination, and it was found that imidazolium ionic liquids destabilized the radical cation of 3-phenylth-

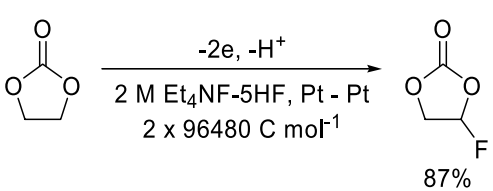

Scheme 7

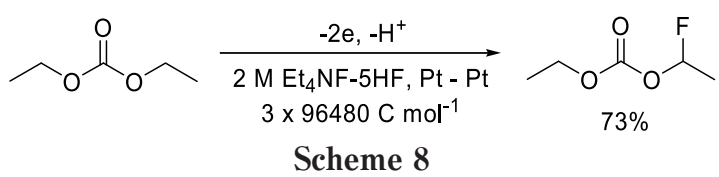

Scheme 5

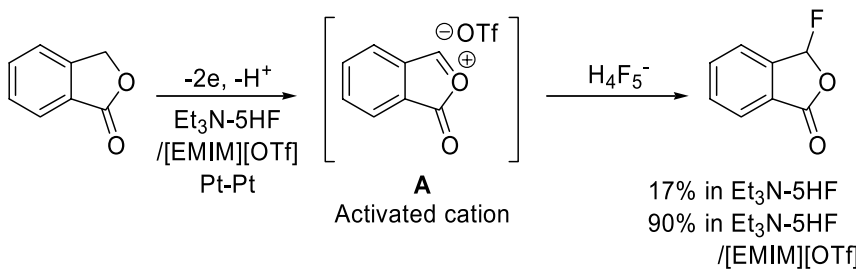

Scheme 9 


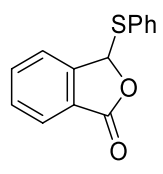

2

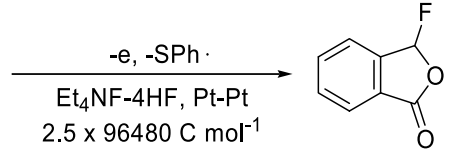

1st cycle: $99 \%, 2$ nd cycle: $96 \%$ 3rd cycle: $93 \%$, 4 th cycle: $94 \%$

Scheme 10

iophthalide (2) resulting in efficient fluorodesulfurization similarly to dichloromethane. ${ }^{41)}$ We have also achieved anodic fluorodesulfurization of $\mathbf{2}$ in ionic liquid $\mathrm{Et}_{4} \mathrm{NF}$. $4 \mathrm{HF}$, and the ionic liquid was reused several times (Scheme 10). ${ }^{42)}$

\section{2 Electrochemical Polymerization in Ionic Liquids}

Recently, Mattes and we have achieved independently anodic polymerization of pyrrole, thiophene, and aniline in different moisture-stable imidazolium ionic liquids. ${ }^{43-45)}$ Mattes found that $\pi$-conjugated polymers prepared in ionic liquids are highly stable so that they can be electrochemically cycled in the ionic liquids up to a million cycles. ${ }^{43)}$ Moreover, since the polymers have cycle switching speeds as fast as $100 \mathrm{~ms}$, they can be used as electrochemical actuators and numeric displays.

We employed [EMIM][OTf] for the anodic polymerization, and we found that the polymerization of pyrrole in the ionic liquid proceeds much faster than that in conventional media like aqueous and acetonitrile solutions containing [EMIM][OTf] as a supporting electrolyte. ${ }^{44,45)}$ It is notable that the surface of the polypyrrole film prepared in neat [EMIM][OTf] is so smooth that no grains are observed in the SEM, while those prepared in aqueous and acetonitrile solutions are very rough.

As summarized in Table 1, both the electrochemical capacity and electroconductivity are markedly increased when the polypyrrole and polythiophene films are prepared in the ionic liquid. This may be attributable to the extremely high concentration of anions as the dopants, which results in much higher doping level.

As described above, the polymer films prepared in the ionic liquid have higher electrochemical density and a highly regulated morphological structure, therefore, their possible utilization is expected as high-performance electrochemical capacitors, ${ }^{46)}$ ion-sieving films, ion-selective electrodes, and so on. The ionic liquid was also demon- strated to be a recyclable medium for the polymerization. ${ }^{45)}$

\section{3 Other Electroorganic Reactions}

Recently, we have achieved electrocatalytic dehalogenation of vic-dihalides using a cobalt salen complex in $[\mathrm{BMIM}]\left[\mathrm{BF}_{4}\right]{ }^{47)}$ We also found that photocatalytic degradation of organic pollutants like dye stuff was markedly enhanced in hydrophobic ionic liquids. ${ }^{48)}$ Electrocatalytic homo- and cross-couplings of organic halides were performed using nickel complexes in imidazolinium ionic liquids. $^{49,50)}$ Electrocatalytic oxidation of alcohols in an ionic liquid containing an ionized N-oxyl radical was also reported. ${ }^{51)}$

\section{Conclusions}

Electroorganic synthesis has been recognized as an environmentally friendly process since late last century. As overviewed briefly, many efforts have been made to develop new methodologies toward green sustainable organic electrode processes. Due to limited space, electrosynthesis in supercritical fluids is not described. ${ }^{52-54)}$ It is hoped that this article will inspire not only electrochemists but also organic chemists to turn to the new and exciting area of modern organic electrochemistry.

\section{Acknowledgement}

This work was financially supported by a Grant-in-Aid for Scientific Research in Priority Areas "Science of Ionic Liquid" (No.17073008) from MEXT, Japan and a Grant-inAid for Scientific Research (No. 16550090, 17750144) from JSPS, Japan. We also thank Nissan Motor Co., Mizuho Foundation for the Promotion of Sciences, The Foundation "Hattori-Hokokai", and Venture Business Laboratory, Tokyo Institute of Technology, for their financial support. We are also grateful to Dr. Mahito Atobe, a lecturer of Tokyo Institute of Technology for his valuable suggestions and contribution to our projects.

\section{References}

1) Organic Electrochemistry (Eds. H. Lund and O. Hammerich), 4th ed., Marcel Dekker, New York, NY (2001).

2) Organic Electrochemistry, Encyclopedia of Electrochemistry, Vol. 8 (Ed. H. Schäfer), Wiley-VCH, Weinheim (2004).

3) H. Hannebaum and H. Putter, WO97/43464,20.11.97.

Table 1 Physical Properties of Polypyrrole and Polythiophene Films Prepared in Various Media.

\begin{tabular}{|c|c|c|c|c|c|}
\hline Polymer & Media & $\begin{array}{c}\text { Roughness } \\
\text { Factor }{ }^{\mathrm{a}} \\
\text { Dimensional }\end{array}$ & $\begin{array}{c}\text { Electrochemical } \\
\text { Capacity/C cm }{ }^{-3}\end{array}$ & $\begin{array}{l}\text { Electroconductivity/ } \\
\qquad \mathrm{S} \mathrm{cm}^{-1}\end{array}$ & $\begin{array}{c}\text { Doping } \\
\text { Level }(\%)^{\mathrm{b}}\end{array}$ \\
\hline Polypyrrole & $\mathrm{H}_{2} \mathrm{O}$ & 3.4 & 77 & $1.4 \times 10^{-7}$ & 22 \\
\hline Polypyrrole & $\mathrm{MeCN}$ & 0.48 & 190 & $1.1 \times 10^{-6}$ & 29 \\
\hline Polypyrrole & [EMIM][OTf] & 0.29 & 250 & $7.2 \times 10^{-2}$ & 42 \\
\hline Polythiophene & $\mathrm{MeCN}$ & 8.6 & 9 & $4.1 \times 10^{-8}$ & - \\
\hline Polythiophene & [EMIM][OTf] & 3.3 & 45 & $1.9 \times 10^{-5}$ & - \\
\hline
\end{tabular}

a Roughness factor is standard deviation of the film thickness.

${ }^{\mathrm{b}}$ The doping level was determined by elemental analysis. 
4) F. Beck and H. Guthke, Chem. Ing. Technol., 41, 943 (1969).

5) J. Yoshida, R. Nakai, and N. Kawabata, J. Org. Chem., 45, 5269 (1980).

6) Z. Ogumi, T. Mizoe, C. Zhen, and Z. Takehara, Bull. Chem. Soc. Jpn., 63, 3365 (1990).

7) H. Tanaka, Y. Kawakami, K. Goto, and M. Kuroboshi, Tetrahedron Lett., 42, 445 (2001).

8) K. Chiba, Y. Kono, S. Kim, Y. Kitano, and M. Tada, Proc. Electrochem. Soc., 2002-10, 9 (2002).

9) R. Horcajada, M. Okajima, S. Suga, and J. Yoshida, Chem. Commun., 20051303.

10) D. Horii, M. Atobe, T. Fuchigami, and F. Marken, J. Electrochem. Soc., 153, 143 (2006).

11) K. D. Kreuer, A. Fuchs, M. Ise, M. Spaeth, and J. Maier, Electrochim. Acta, 43, 1281 (1998).

12) T. Tajima and T. Fuchigami, J. Am. Chem. Soc., 127, 2848 (2005).

13) T. Tajima and T. Fuchigami, Chem. Eur. J., 11, 6192 (2005).

14) T. Tajima and T. Fuchigami, Angew. Chem. Int. Ed., 44, 4670 (2005).

15) C. Iwakura, T. Abe, and H. Inoue, J. Electrochem. Soc., 143, L71 (1996).

16) H. Inoue, Y. Yoshida, S. Ogata, T. Shimamune, and C. Iwakura, J. Electrochem. Soc., 143, L71 (1996).

17) S. Maki, Y. Harada, T. Hirano, H. Niwa, Y. Yoshida, S. Ogata, S. Nakamatsu, H. Inoue, and C. Iwakura, Syn. Commun., 30, 3575 (2000).

18) H. Tajima, H. Ishii, and T. Fuchigami, $70^{\text {th }}$ Annual Meeting of the Electrochemical Society of Japan, Abstr., p.16 (2003).

19) T. Welton, Chem. Rev. 99, 207 (1999).

20) P. Wassersheid and W. Keim, Angew. Chem. Int. Ed., 39, 3772 (2000).

21) Green Industrial Applications of Ionic Liquids (Ed. R. D. Rogers, K. R. Seddon, and S. Volkov), Kluwer Academic Publishers (2002).

22) H. Ishii and T. Fuchigami, Electrochemistry, 70, 46 (2002) [in Japanese].

23) T. Fuchigami and M. Atobe, Materials Integration, 16, 20 (2003) [in Japanese].

24) T. Fuchigami, Electrochemical Aspects of Ionic Liquids (Ed. H. Ohno), John Wiley \& Sons (2004), Chap. 8.

25) T. Fuchigami, Advances in Electron Transfer Chemistry (Ed. P. S. Mariano), Vol.6, JAI Press, Stanford, CN (1999), p. 41.

26) T. Fuchigami, Organic Electrochemistry (Eds. H. Lund and O. Hammerich), 4th ed., Marcel Dekker, New York, NY (2001), Chap. 25.

27) T. Fuchigami and T. Tajima, Fluorine-Containing Synthones (Ed. V. A. Soloshonok), American Chemical Society, Washington, DC (2005), Chap. 15.

28) Our most recent publication: T. Tajima, A. Nakajima, and T. Fuchigami, J. Org. Chem., 71, 1436 (2006).

29) T. Fuchigami, M. Shimojo, A. Konno, and K. Nakagawa,
J. Org. Chem. 55, 6074 (1990).

30) T. Fuchigami, T. Sunaga, H. Ishii, and M. Atobe, $201^{s t}$ Meeting of The Electrochemical Society, Abstr. No. 1220 (2002).

31) K. Momota, M. Morita, and Y. Matsuda, Electrochim. Acta, 38, 1123 (1993).

32) K. Momota, T. Yonezawa, Y. Hayakawa, K. Kato, M. Morita, and Y. Matsuda, J. Appl. Electrochem., 25, 651 (1995).

33) S. -Q. Chen, T. Hatakeyama, T. Fukuhara, S. Hara, and N. Yoneda, Electrochim. Acta, 42, 1951 (1997).

34) S. Hara, S. Q. Chen, T. Hoshio, T. Fukuhara, and N, Yoneda, Tetrahedron Lett., 37, 8511 (1996).

35) M. Hasegawa, H. Ishii, and T. Fuchigami, Tetrahedron Lett., 43, 1502 (2002).

36) M. Hasegawa, H. Ishii, and Y. Cao, and T. Fuchigami, J. Electrochem. Soc., in press.

37) M. Hasegawa, H. Ishii, and T. Fuchigami, Green Chem., 5, 512 (2003).

38) Y. Hou and T. Fuchigami, J. Electrochem. Soc., 147, 4567 (2000).

39) M. R. Shaaban, H. Ishii, and T. Fuchigami, J. Org. Chem., 65, 8685 (2000).

40) H. Ishii, N. Yamada, and T. Fuchigami, Chem. Commun., 20001617.

41) T. Fuchigami and T. Tajima, J. Fluorine Chem., 126, 181 (2005).

42) M. Hasegawa and T. Fuchigami, Electrochim. Acta, 49, 3367 (2004).

43) W. Lu, A. G. Fadeev, B. Qi, E. Smela, B. R. Mattes, J. Ding, G. M. Spinks, J. Mazurkiewicz, D. Zhou, G. G. Wallace, D. R. MacFarlane, S. A. Forsyth, and M. Forsyth, Science, 297, 983 (2002).

44) K. Sekiguchi, M. Atobe, and T. Fuchigami, Electrochem. Commun., 4, 881 (2002).

45) K. Sekiguchi, M. Atobe, and T. Fuchigami, J. Electroanal. Chem., 557, 1 (2003).

46) K. Naoi, Y. Ota, and K. Machida, Electrochemistry, 74, 53 (2006) [in Japanese].

47) Y. Shen, T. Tajima, M. Atobe, and T. Fuchigami, Electrochemistry, 72, 849 (2004).

48) K. Sekiguchi, M. Atobe, and T. Fuchigami, Electrochemistry, 72, 839 (2004).

49) M. Mellah, S. Gmouh, M. Vaultier, and V. Jouikov, Electrochem. Commun., 5, 591 (2003).

50) R. Barhdadi, C. Courtinard, J. Y. Nedelec, and M. Troupel, Chem. Commun., 20031434.

51) M. Kuroboshi, J. Fujisawa, and H. Tanaka, Electrochemistry, 72, 846 (2004).

52) M. Tokuda, Electrochemistry, 67, 993 (1999) [in Japanese].

53) P. E. Anderson, R. N. Badlan, J. Mayer, and P. A. Mbrouk, J. Am. Chem. Soc., 124, 10284 (2002).

54) M. Atobe, H. Ohsuka, and T. Fuchigami, Chem. Lett., 2004, 618 . 